\title{
Phylogeography and Demographic History of Amblyomma variegatum (Fabricius) (Acari: Ixodidae), the Tropical Bont Tick
}

\author{
Lorenza Beati,, Jaymin Patel, ${ }^{1}$ Helene Lucas-Williams, ${ }^{2}$ Hassane Adakal, ${ }^{3}$ \\ Esther G. Kanduma, ${ }^{4}$ Enala Tembo-Mwase, ${ }^{5}$ Rosina Krecek, ${ }^{2,6}$ James W. Mertins, ${ }^{7}$ \\ Jeffery T. Alfred, ${ }^{7}$ Susyn Kelly, ${ }^{2}$ and Patrick Kelly ${ }^{2}$
}

\begin{abstract}
The genetic diversity of Amblyomma variegatum (Fabricius) from four Caribbean islands and five African countries was compared by analyzing the sequences of three gene fragments, two mitochondrial (12SrDNA and D-Loop-DL), and one nuclear (intergenic transcribed spacer 2 [ITS2]). Genetic variability of the ITS2 DNA fragment consisted of only uninformative single nucleotide mutations, and therefore this gene was excluded from further analyses. Mitochondrial gene divergences among African populations and between Caribbean and African populations were very low. Nevertheless, the data suggest that A. variegatum is divided into distinct East and West African groups, the western group including all Caribbean samples. Phylogenetic analyses of the $12 \mathrm{SrDNA}$ and DL gene sequences showed that the West African A. variegatum clustered in a well-supported monophyletic clade, distinct from eastern paraphyletic lineages. Sequences of $A$. variegatum from the Caribbean were embedded in the West African clade, which supports the known West African historical origin for these ticks.
\end{abstract}

Key Words: Amblyomma variegatum-Population genetics.

\section{Introduction}

$T^{\mathrm{s}}$ HE tropical BONT тіск, Amblyomma variegatum (Fabricius) (Acari: Ixodidae), is widely distributed in the Caribbean Basin and in sub-Saharan Africa, where it occurs in different ecosystems separated by important geographical barriers (Walker and Olwage 1987; Barré et al. 1995; EstradaPeña et al. 2007). A. variegatum was probably introduced from West Africa to Guadeloupe on imported cattle in the 18th or the 19th centuries (Uilenberg et al. 1984; Maillard and Maillard 1998). It remained confined to Guadeloupe, Marie Galante, and Antigua, until 1948, when it invaded Martinique. Thereafter it spread rapidly, extending its distribution to 18 Caribbean islands (Barré et al. 1995; Maillard and Maillard 1998). This rapid dispersal was coincident with the intro- duction of the cattle egret, Bubulcus ibis (Linnaeus), in the region (Barré et al. 1995). Egrets can be infested with larvae and occasionally nymphs of $A$. variegatum, and they migrate widely in the Caribbean, even as far as the Florida Keys (Corn et al. 1993).

In Africa and the Caribbean, A. variegatum causes substantial economic losses in domestic ruminants by exsanguination or physical injury; by transmitting Ehrlichia ruminantium (Cowdry), the agent of heartwater; and by association with dermatophilosis (Barré et al. 1995; Camus and Barré 1995; Molia et al. 2008). This tick also carries Rickettsia africae, the agent of African tick bite fever in humans, in Africa and the Caribbean (Kelly et al. 1996; Parola et al. 1999; Kelly et al. 2010). Because of its local importance and potential spread to the United States (Deem 1998), A. variegatum has been the subject of various

\footnotetext{
${ }^{1}$ Institute of Arthropodology and Parasitology, Georgia Southern University, Statesboro, Georgia.

${ }^{2}$ Ross University School of Veterinary Medicine, St. Kitts and Nevis, West Indies.

${ }^{3}$ CIRDES, Bobo-Dioulasso, Burkina Faso.

${ }^{4}$ Department of Biochemistry, University of Nairobi, and Biosciences Eastern and Central Africa (Hub) at International Livestock Research Institute (ILRI), Nairobi, Kenya.

${ }^{5}$ School of Veterinary Medicine, Pre-Clinical Studies, University of Zambia, Lusaka, Zambia.

${ }^{6}$ Department of Zoology, University of Johannesburg, Auckland Park, South Africa.

${ }^{7}$ United States Department of Agriculture, Animal and Plant Health Inspection Service, Veterinary Services, National Veterinary Services Laboratories, Ames, Iowa.
} 
eradication and control programs since 1994 (Barré et al. 1996; Pegram et al. 1998). These have resulted in the apparent absence of the tick from several islands (Pegram et al. 2004), but in many cases it has recurred, possibly because of incomplete eradication or reintroduction.

Having a means of tracking tick migration to and from different areas would facilitate attempts to establish the cause of eradication failure. Genetic markers would be one means of doing so, but currently little is known about the population structure of A. variegatum. It is known, however, that the genetically diverse genotypes of E. ruminantium in the Caribbean are linked to a number of different African origins (Vachiéry et al. 2008). Locally high levels of genetic diversity in E. ruminantium strains have also been reported from Burkina Faso (Adakal et al. 2009). These findings suggest that several strains of E. ruminantium were introduced with A. variegatum in the 19th century (Vachiéry et al. 2008). As single animals reportedly can be infected with multiple E. ruminantium genotypes (Allsopp et al. 2007) and be healthy carriers for months (Andrew and Norval 1989), the concomitant importation of different pathogenic genotypes is unsurprising.

Genetic variability in ticks can be associated with their ability to transmit pathogens (Qiu et al. 2002; McCoy 2008), and therefore the possibility that genetically diverse populations of A. variegatum, with different vectorial competences, have colonized different areas of the Caribbean must be considered.

To investigate the phylogeographical history of $A$. variegatum, sequences of two mitochondrial and one nuclear gene were compared in ticks collected on several Caribbean islands and also in five African countries.

\section{Materials and Methods}

\section{Sampling}

Our study material included adult ticks (numbers per locality are in parentheses) collected from cattle from Kenya (40), Zambia (33), Mali (17), Burkina Faso (30), and Ethiopia (2) in Africa; and from St. Kitts (9), Dominica (32), Montserrat (3), and the United States Virgin Islands (19) in the Caribbean. One adult Amblyomma hebraeum Koch from South Africa was used as outgroup for phylogenetic analyses.

\section{DNA extraction, PCR, and sequencing}

DNA was extracted according to a previously published protocol (Beati et al. 1995,2004; Beati and Keirans 2001). The cuticle of each tick was preserved during DNA extraction, so that future morphological examinations would be possible. This involved separation of about a third of the posterolateral idiosoma of each tick with a disposable scalpel, followed by overnight incubation of the entire tick in $180 \mu \mathrm{L}$ of Qiagen ATL lysis buffer (Qiagen, Valencia, CA), and $40 \mu \mathrm{L}$ of $14.3 \mathrm{mg} / \mathrm{mL}$ proteinase K (Roche Applied Sciences, Indianapolis, IN). Repeated vortexing facilitated complete lysis of internal tick tissues, which were further processed as previously described (Beati and Keirans 2001). The remaining tick cuticular parts were preserved in $70 \%$ alcohol for potential future examination. A 360-base pair (bp) fragment of the 12SrDNA sequence, corresponding to part of domain II and domain III of the ribosomal small-subunit RNA gene sequence (Hickson et al. 1996), was amplified by primers T1B ( $5^{\prime}$-aaa cta gga tta gat acc ct- $\left.3^{\prime}\right)$ and T2A (5'-aat gag agc gac ggg cga tgt- $3^{\prime}$ ) (Beati and
Keirans 2001). Primers for the amplification of the control region or D-Loop (DL), DLIx3 (5'-taa ccg ckg ckg ctg gca caa-3') and DLIx4 (5'-aga taa ycc ttt ayt cag gca t- $\left.3^{\prime}\right)$, were chosen by comparing the complete mitochondrial genome sequences of Rhipicephalus sanguineus (Latreille) (GeneBank accession number NC 002074.1), and Ixodes hexagonus Leach (GenBank accession number NC 002010.1) (Black and Roehrdanz 1998). DLIx3 was selected within the 12SrDNA gene sequence (position 13890-13910), and DLIx4 within the tRNA-Ile gene (position 14434-14413) of the I. hexagonus mitochondrial genome. Intergenic transcribed spacer 2 (ITS2) sequences were amplified using a previously published primer located in the 5.8SrDNA region (McLain et al. 1995), and primer ITS2R2, which was selected in the 28SrDNA region of Ixodes loricatus Neumann (AF327344; bp 946-961). Amplifications were performed in an Eppendorf Master cycler (Fisher Scientific, Inc., Pittsburgh, PA). The 12SrDNA thermal cycling program involved a touchdown first step, with annealing temperatures decreasing from $60^{\circ} \mathrm{C}$ to $50^{\circ} \mathrm{C}$ for $25 \mathrm{sec}$ (elongation from $72^{\circ} \mathrm{C}$ to $68^{\circ} \mathrm{C}$ for $30 \mathrm{sec}$ ) over 5 cycles, followed by 30 cycles, with annealing temperature at $49^{\circ} \mathrm{C}$ (for $35 \mathrm{sec}$ ), and elongation temperature at $68^{\circ} \mathrm{C}$ (for $30 \mathrm{sec}$ ). The DL program started with a touchdown step, with temperatures decreasing from $55^{\circ} \mathrm{C}$ to $47^{\circ} \mathrm{C}$ for $30 \mathrm{sec}$ over four cycles (elongation decreasing from $70^{\circ} \mathrm{C}$ to $67^{\circ} \mathrm{C}$ for $60 \mathrm{sec}$ ), followed by 31 cycles with annealing temperature at $46^{\circ} \mathrm{C}$ for $35 \mathrm{sec}$ (elongation at $66^{\circ} \mathrm{C}$ for $45 \mathrm{sec}$ ). The amplification protocol for the ITS2 gene sequences consisted of an initial touchdown step, with annealing temperatures decreasing from $65^{\circ} \mathrm{C}$ to $54^{\circ} \mathrm{C}$ for 20 sec over eight cycles (elongation from $72^{\circ} \mathrm{C}$ to $70^{\circ} \mathrm{C}$ for $90 \mathrm{sec}$ ), and 27 cycles with annealing temperature at $53^{\circ} \mathrm{C}$ for $30 \mathrm{sec}$ and elongation at $70^{\circ} \mathrm{C}$ for $90 \mathrm{sec}$. The amplicons were purified and both strands were sequenced, with the same primers used for PCR, at the High-Throughput Genomics Unit (HTGU; University of Washington, Seattle, WA). They were assembled with Sequencer 4.5 (Gene Codes Corporation, Ann Arbor, MI) and submitted to GenBank.

\section{Voucher specimens}

For each geographic sample, United States National Tick Collection accession numbers (RML) for the preserved cuticles and GenBank accession numbers for the corresponding sequences were: Montserrat RML 124493-494 (12SrDNA: HQ856471-HQ856472; DL: HQ856589-HQ856591; ITS2: HQ856761-HQ856763); Dominica RML 124496-501 (12SrDNA: HQ856467-HQ856469, HQ856692-HQ856710; DL: HQ856580HQ856587; ITS2: HQ856730-HQ856750); St. Kitts RML 124816 (12SrDNA: HQ856490, JF826430-JF826437; DL: HQ856600HQ856608; ITS2: HQ856764-HQ856768); United States Virgin Islands RML 124502 (12SrDNA: HQ856515-HQ856525; DL: HQ856644-HQ856652; ITS2: HQ856791-HQ856802); Mali RML 124812 (12SrDNA: HQ856473-HQ856489; DL: HQ856592HQ856599; ITS2: HQ856753-HQ856759); Burkina Faso RML 124813 (12SrDNA: HQ856554-HQ856579; DL: HQ856677HQ856689; ITS2: HQ856711-HQ856729); Kenya RML 124811 (12SrDNA: HQ856491-HQ856514; DL: HQ856609-HQ856643; ITS2: HQ856769-HQ856790); Zambia RML 124810 (12SrDNA: HQ856526-HQ856553; DL: HQ856653-HQ856661, HQ856663HQ856676; ITS2: HQ856805-HQ856822); Ethiopia RML 91652 (12SrDNA:HQ856466; DL: HQ856588; ITS2: HQ856751, HQ856752). 


\section{Phylogeographical analysis}

Sequences were manually aligned with McClade 4.07 (Sinauer Associates, Sunderland, MA) (Maddison and Maddison 2000). Secondary structure was considered in aligning 12SrDNA (Beati and Keirans 2001), and DL (Zhang and Hewitt 1997). Haplotypes were considered to be distinct when they differed by at least one base pair (indels included). Relationships between haplotypes were investigated by generating unrooted haplotype networks using statistical parsimony software TCS version 1.13 (Clement et al. 2000), with a confidence level of $95 \%$ and indels treated as fifth characters.

\section{Phylogenetic analyses}

Each data set was also analyzed by maximum parsimony (MP) with PAUP, and Bayesian analysis (BA) with MrBayes 2.01 (Huelsenbeck et al. 2001). Homogeneity of base frequencies across our samples was evaluated with a $\chi^{2}$ goodness-of-fit test using PAUP 4.0b10 (Swofford 2000) before all phylogenetic analyses. Branch support was assessed by bootstrap analysis (1000 replicates) with PAUP and posterior probability with MrBayes. MP heuristic searches were performed by branchswapping, using the tree bisection-reconnection (TBR) algorithm, ACCTRAN character optimization, with all substitutions given equal weight, gaps treated as missing characters, and with 10 random sequence addition replicates. Sequence divergence was calculated by maximum likelihood in PAUP, after evaluating the substitution model best fitting the data with Modeltest 3.7 (Posada and Crandall, 1998). Two runs, with four chains each, were processed simultaneously for BA $(1,000,000$ generations). Trees were sampled at every 100 th iteration. Trees saved before the average standard deviation of split fragments converged to a value $\leq 0.01$ were discarded from the final sample series. The $50 \%$ majority-rule consensus tree of the remaining trees was inferred, and posterior probabilities were recorded for each branch.

\section{Haplotype statistical analyses}

The data matrices (indels excluded) were imported in ARLEQUIN 3.0 (Schneider et al. 2000; Excoffier et al. 2005), which was used to calculate the number of observed/unique haplotypes (k), the number of segregating/polymorphic sites $(S)$, haplotype diversity (gene diversity), and nucleotide diversity per site $(\pi)$. Deviations from neutrality expectations were tested with Tajima's D statistics (Tajima 1989) and Fu's Fs statistics (Fu 1997), also in ARLEQUIN. To test for population structure among samples, an analysis of molecular variance (AMOVA) was performed in ARLEQUIN, with the significance of fixation indices evaluated through a nonparametric approach (Excoffier et al. 1992). Population pairwise genetic differentiation/distances $\left(\Phi_{\mathrm{ST}}\right)$ were calculated and their significance was tested using 1000 permutations (Schneider et al. 2000). The non-random distribution of haplotypes in A. variegatum populations was determined with an exact test of population differentiation (Raymond and Rousset 1995). Historical patterns of population structure also were investigated, using the mismatch distribution of pairwise genetic differences implemented in ARLEQUIN, which compared the observed distribution with that expected under a model of population expansion (Rogers 1995).

\section{Results}

\section{Haplotype diversity}

Alignment of the 142 12SrDNA-derived gene sequences resulted in a $344 \mathrm{bp}$ data matrix. The sequences consisted of 19 unique haplotypes (11 when indels were excluded). Of these, only three (haplotypes $A, H$, and $L$ ) were found in more than one country. Haplotypes $A$ and $L$ were the most common haplotypes found in West and East Africa, respectively. All Caribbean haplotypes, with the exception of the unique haplotype $B$ from Dominica, were identical to haplotypes from either Burkina Faso or Mali. Although distinct, haplotype $B$ was closely related to West African sequences and differed from $A$ by a single indel position (Table 1). Of the 344 nucleotides, after deleting indels, only 18 (5.2\%) were polymorphic. Within the different studied populations, the number of segregating sites per population varied from two (Caribbean) to 13 (East Africa) (Table 2). The TCS-generated phylogenetic network based upon 12SrDNA haplotypes (Fig. 1) revealed that there is a predominant West African/ Caribbean haplotype found in five countries (Montserrat, United States Virgin Islands, St. Kitts, Mali, and Burkina Faso). None of the Caribbean haplotypes clustered with East African samples. Other West African sequences differed by two steps at most from the predominant haplotype, and the differences were chiefly indels. In general, there were more haplotypes in Mali and Burkina Faso than in the Caribbean. The star-shaped tree topology of the West African/Caribbean haplotypes, with a predominant haplotype surrounded by haplotypes that differed mostly by a single base pair, suggests a recent population expansion. The East African haplotypes displayed a loop-shaped structure, and they were more distinct from each other (up to 11 steps), indicating an older evolutionary history. An intermediate group, consisting of two Zambian haplotypes ( $J$ and $K$ ), was closer to the West African/Caribbean (2-7 steps) than the East African haplotypes (9-17 steps).

The DL data matrix contained 110 sequences (342 bp) with 17 unique haplotypes (14 when indels were excluded) (Table 3). Common haplotypes were found in Burkina Faso and Mali (V), and Burkina Faso and Dominica (II) (Table 3). The Montserrat, St. Kitts, and United States Virgin Island haplotypes were found only in the Caribbean. Kenya, Zambia, and Ethiopia shared haplotype X. In general, the topology of the haplotype network (Fig. 2) generated with TCS was very similar to that in seen Figure 1. However, unlike 12SrDNA data, some of the DL sequences of Montserrat, the United States Virgin Islands, and St. Kitts (haplotypes III and IV) showed further divergence from the West African sequences than those from Dominica, which were identical to two haplotypes from Burkina Faso. The DL haplotype IX from Zambia corresponded to $12 S$ haplotypes $J$ and $K$, and fell at equal distance (two mutations) between West and East African clusters. Overall, the diversity among western haplotypes (mostly six steps), and among East African haplotypes (five steps), was similar. Among the most common East African haplotypes, haplotype XI was found only in Kenya, and haplotype XVII only in Zambia, but haplotype X was distributed in three different countries.

The 1041-bp ITS2 data matrix contained 112 sequences. The sequences were all identical except for 7 samples, which differed from the consensus sequence by singleton, 




uninformative base pairs. Therefore these sequences could not be used for any systematic or biogeographical inferences.

\section{Phylogenetic analyses}

The MP analysis for the 12SrDNA sequences detected 11 parsimony informative sites, and an MP heuristic search found 15 equally parsimonious trees (length $=47, \mathrm{CI}=0.839$, $\mathrm{RI}=0.872, \mathrm{RC}=0.731$, and $\mathrm{HI}=0.161$ ) in a single island. Base frequencies were statistically homogeneous across the matrix $\left(\chi^{2}=1.7 ; \mathrm{df}=57, \mathrm{p}=1.0\right)$. The maximum likelihood model best fitting the data by use of the Akaike Information Criterion (AIC) was the HKY $+\mathrm{I}$, with base frequencies of $\mathrm{A}=0.42$, $\mathrm{C}=0.07, \mathrm{G}=0.12$, and $\mathrm{T}=0.39$; transition/transversion rate $=$ 1.075; and proportion of invariable sites of 0.81 , with equal rates. Maximum likelihood genetic divergences between outgroup and ingroup taxa varied from $15.7-25.1 \%$. Sequences from West African, Caribbean, and Zambian haplotypes J and $K$ differed from each other at most by $0.6 \%$. The remaining East African haplotypes differed from each other by $0-1.2 \%$, and from the West African haplotypes by $1.9-4.0 \%$. Topologies of the trees obtained by MP and BA were identical, and therefore Figure 3A shows only the BA phylogenetic reconstruction. Overall resolution of the trees was relatively poor, due to the low number of informative characters. Nevertheless, all the Caribbean haplotypes, the West African haplotypes, and haplotypes $\mathrm{J}$ and $K$ were clustered in a monophyletic clade (clade a), with the Zambian haplotypes placed in a basal position within this western clade. The other East African samples were basal to the western clade and paraphyletic.

The DL MP analysis detected 12 parsimony informative sites, and MP heuristic search found 14 equally parsimonious trees (length $=53, \mathrm{CI}=0.887, \mathrm{RI}=0.889, \mathrm{RC}=0.788$, and $\mathrm{HI}=0.113)$ in a single island. Base frequencies were statistically homogeneous across the matrix $\left(\chi^{2}=1.32 ; \mathrm{df}=51\right.$, $p=1.0)$. The maximum likelihood model best fitting the data by use of the AIC was the HKY + I, with base frequencies of $\mathrm{A}=0.42, \mathrm{C}=0.11, \mathrm{G}=0.14$, and $\mathrm{T}=0.33$; transition/transversion rate $=2.252$; and proportion of invariable sites of 0.83 , with equal rates. Maximum likelihood genetic divergences between $A$. hebraeum and these $A$. variegatum sequences varied from $16.7 \%$ to $20.1 \%$. Differences between sequences from West African, Caribbean, and Zambian haplotype IX amounted at most to $1.5 \%$. The additional East African haplotypes differed from each other by $0-1.2 \%$, and from the West African haplotypes by $1.4 \%$ to $2.8 \%$ (1.2\% with Zambian haplotype IX). The tree shown in Figure 3B depicts the BA results only, because the phylogenetic DL trees inferred by MP and BA were structurally identical. This BA tree also was poorly resolved, with posterior probabilities and bootstrap values slightly higher than those calculated for the 12SrDNA reconstruction (Fig. 3A). Relationships between the main lineages were nevertheless fully congruent with those revealed by analyzing 12SrDNA gene sequences, with East African lineages being paraphyletic and basal to a monophyletic clade (clade b1) containing all the West African, Caribbean, and Zambian IX haplotypes. Unlike the $12 \mathrm{~S}$ reconstruction, the Zambian intermediate haplotypes constituted a separate monophyletic group within a1 (clade b2). An additional well-resolved clade (clade c) was identifiable within the East African lineages and contains only Kenyan specimens. 
Table 2. Descriptive Statistics of Studied Amblyomma variegatum 12SrDNA Haplotypes

\begin{tabular}{|c|c|c|c|c|c|c|c|c|c|}
\hline & & & & & & & Tajima's test & Fu's Test & \\
\hline Region & Ns & $s$ & $k$ & $m p d \pm S D$ & $H d \pm S D$ & $\pi \pm S D$ & $D(\mathrm{p})$ & $F S(\mathrm{p})$ & $R g(\mathrm{p})$ \\
\hline West Africa & 43 & 8 & 6 & $0.86 \pm 0.62$ & $0.338 \pm 0.092$ & $0.0025 \pm 0.0020$ & $-1.435(0.06)$ & $-1.673(0.14)$ & $0.58(0.30)$ \\
\hline East Africa & 53 & 13 & 10 & $2.05 \pm 1.17$ & $0.541 \pm 0.051$ & $0.0065 \pm 0.0038$ & $-0.981(0.15)$ & $2.284(0.85)$ & $0.53(0.02)$ \\
\hline Caribbean & 46 & 2 & 3 & $0.08 \pm 0.16$ & $0.435 \pm 0.041$ & $0.0002 \pm 0.0005$ & $-1.473(0.04)$ & $-0.783(0.11)$ & $0.91(0.94)$ \\
\hline $\begin{array}{c}\text { West Africa + } \\
\text { Caribbean }\end{array}$ & 89 & 8 & 9 & $0.47 \pm 0.41$ & $0.192 \pm 0.056$ & $0.0014 \pm 0.0013$ & $-1.649(0.02)$ & $-2.867(0.06)$ & $0.70(0.51)$ \\
\hline Total & 142 & 18 & 11 & $5.08 \pm 2.48$ & $0.621 \pm 0.036$ & $0.0149 \pm 0.0080$ & $1.194(0.89)$ & $4.155(0.89)$ & $0.49(<0.001)$ \\
\hline
\end{tabular}

Ns, number of sequences; $S$, segregating sites; $\mathrm{k}$, number of observed haplotypes; mpd, mean number of pairwise differences \pm SD, Hd, haplotype or gene diversity $\pm \mathrm{SD} ; \pi$, nucleotide diversity/site $\pm \mathrm{SD} ; \mathrm{Rg}$, raggedness index obtained by mismatch distribution analysis. $p$ Values in parentheses, significant values are in bold. Data obtained after removal of indels.

The concatenated matrix included 75 sequences (776 bp) corresponding to 25 unique haplotypes and one outgroup haplotype. Reconstruction of the relationships between the A. variegatum lineages based on the combined database was characterized by better overall resolution. The MP heuristic search found 168 equally parsimonious trees (length $=123$, $\mathrm{CI}=0.854, \mathrm{RI}=0.909, \mathrm{RC}=0.776$, and $\mathrm{HI}=0.146$ ) in a single island. Base frequencies were statistically homogeneous across the matrix $\left(\chi^{2}=1.23 ; \mathrm{df}=75, p=1.0\right)$. The maximum likelihood model best fitting the data by use of the AIC was the $\mathrm{TIM}+\mathrm{I}$, with base frequencies of $\mathrm{A}=0.42, \mathrm{C}=0.10$, $\mathrm{G}=0.13$, and $\mathrm{T}=0.35$; general time reversible matrix $(1.000$
15.8763 .908 6.507); and proportion of invariable sites of 0.80 , with equal rates. Overall structure of the tree (Fig. 4) had slightly better support for the main clades than the trees generated by separate analyses of the two sampled genes. Paraphyly of the East African lineages was confirmed, although a clade (clade f) containing Kenyan, Ethiopian, and Zambian specimens was delineated as a separate, moderately-supported cluster. Sequences of the Zambian haplotype IX (clade e) are clustered in a separate monophyletic lineage basal to the West African samples (clade d). Within clade d, specimens from Montserrat, the United States Virgin Islands, and St. Kitts further radiated from the polytomic basal

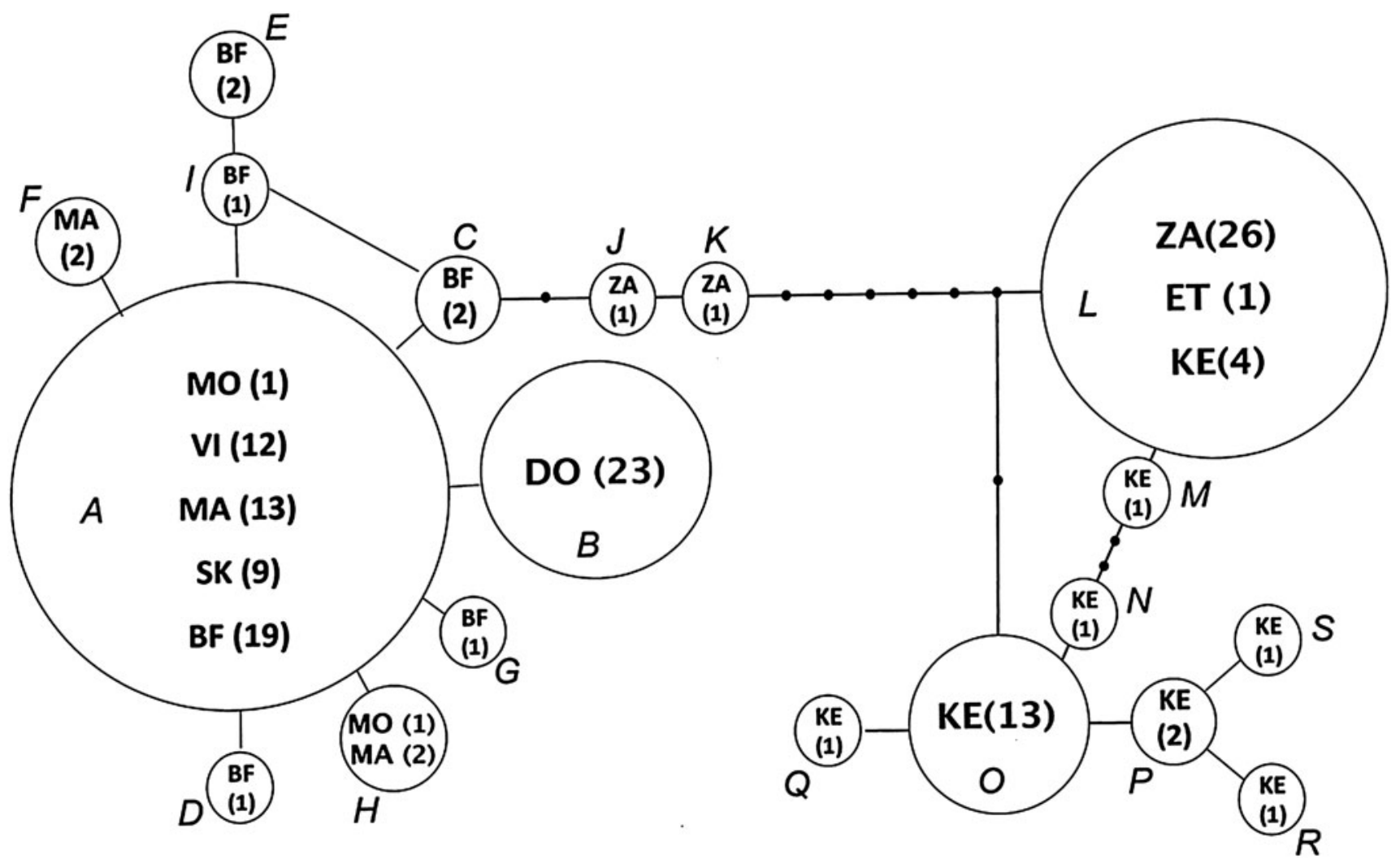

FIG. 1. Unrooted minimum spanning network with a $95 \%$ confidence interval of the 12 SrDNA haplotypes (circles) in studied populations of Amblyomma variegatum. Lines represent single mutations and dots represent unsampled intermediate haplotypes. Origins of the haplotypes and their numbers (in parentheses) are designated as follows: MO, Montserrat; DO, Dominica; VI, U.S. Virgin Islands; MA, Mali; BF, Burkina Faso; SK, St. Kitts; KE, Kenya; ET, Ethiopia; ZA, Zambia. Letters in capital italics cross-reference the haplotypes as listed in Table 2. 
Table 3. Amblyomma variegatum D-Loop (DL) Haplotype Distribution Among Sampling Localities (in Parentheses, Number of Specimens/Frequencies per Haplotype After Removal of Indels)

\begin{tabular}{|c|c|c|c|c|c|c|c|c|c|c|c|c|c|c|c|c|c|c|}
\hline \multirow[b]{2}{*}{ Country } & \multirow[b]{2}{*}{ Ns } & \multicolumn{17}{|c|}{ Haplotypes DL } \\
\hline & & $I$ & II & III & $I V$ & $V$ & $V I$ & $V I I$ & VIII & $I X$ & $X$ & $X I$ & XII & XIII & XIV & $X V$ & $X V I$ & XVII \\
\hline Montserrat & 3 & & & 1 & & $0(2)$ & & $2(0)$ & & & & & & & & & & \\
\hline Dominica & 8 & & 8 & & & & & & & & & & & & & & & \\
\hline U.S. Virgin Islands & 9 & & & & 9 & & & & & & & & & & & & & \\
\hline St. Kitts & 9 & & & 4 & 5 & & & & & & & & & & & & & \\
\hline Burkina Faso & 13 & 1 & $2(3)$ & & & 8 & 1 & & $1(0)$ & & & & & & & & & \\
\hline Mali & 8 & & & & & 8 & & & & & & & & & & & & \\
\hline Ethiopia & 1 & & & & & & & & & & 1 & & & & & & & \\
\hline Kenya & 35 & & & & & & & & & & $6(7)$ & 24 & 1 & 2 & 1 & & $1(0)$ & \\
\hline Zambia & 24 & & & & & & & & & 2 & 8 & & & & & 1 & & 13 \\
\hline Total & 110 & 1 & $10(11)$ & 5 & 14 & $16(18)$ & 1 & $2(0)$ & $1(0)$ & 2 & $15(16)$ & 24 & 1 & 2 & 1 & 1 & $1(0)$ & 13 \\
\hline Frequency (\%) & & 0.9 & $\begin{array}{c}9.1 \\
(10.0)\end{array}$ & 4.5 & 12.7 & $\begin{array}{c}14.5 \\
(16.4)\end{array}$ & 0.9 & $\begin{array}{l}1.8 \\
(0)\end{array}$ & $\begin{array}{l}0.9 \\
(0)\end{array}$ & 1.8 & $\begin{array}{c}13.6 \\
(14.5)\end{array}$ & 21.8 & 0.9 & 1.8 & 0.9 & 0.9 & $\begin{array}{l}0.9 \\
(0)\end{array}$ & 11.8 \\
\hline
\end{tabular}

Ns, number of sequences.

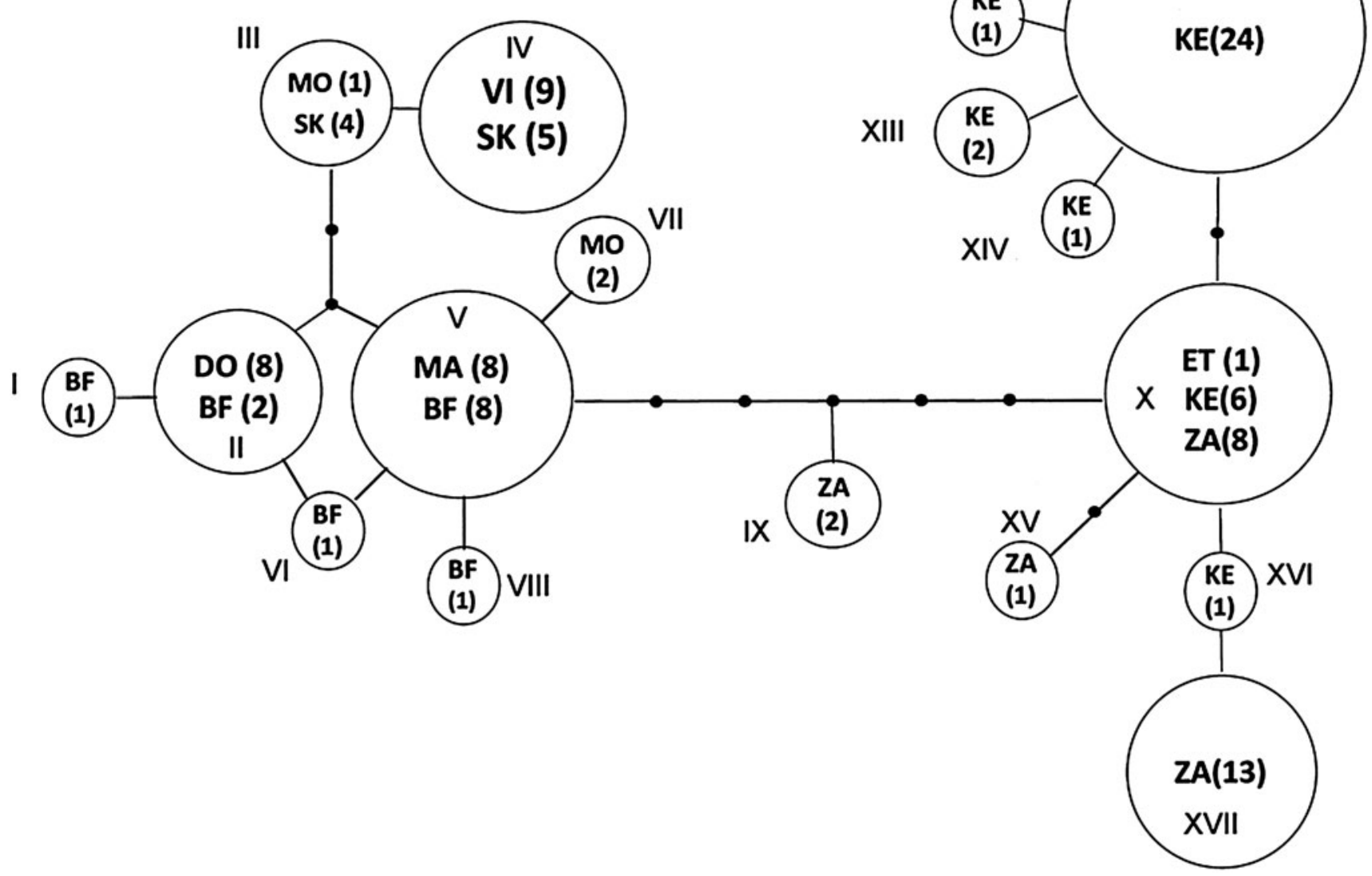

FIG. 2. Unrooted minimum spanning network with a 95\% confidence interval of the D-Loop haplotypes (circles) in studied populations of Amblyomma variegatum. Lines represent single mutations and dots represent unsampled intermediate haplotypes. Origins of the haplotypes and their numbers (in parentheses) are designated as follows: MO, Montserrat; DO, Dominica; VI, U.S. Virgin Islands; MA, Mali; BF, Burkina Faso; SK, St. Kitts; KE, Kenya; ET, Ethiopia; ZA, Zambia. Roman numerals cross-reference the haplotypes as listed in Table 3. 


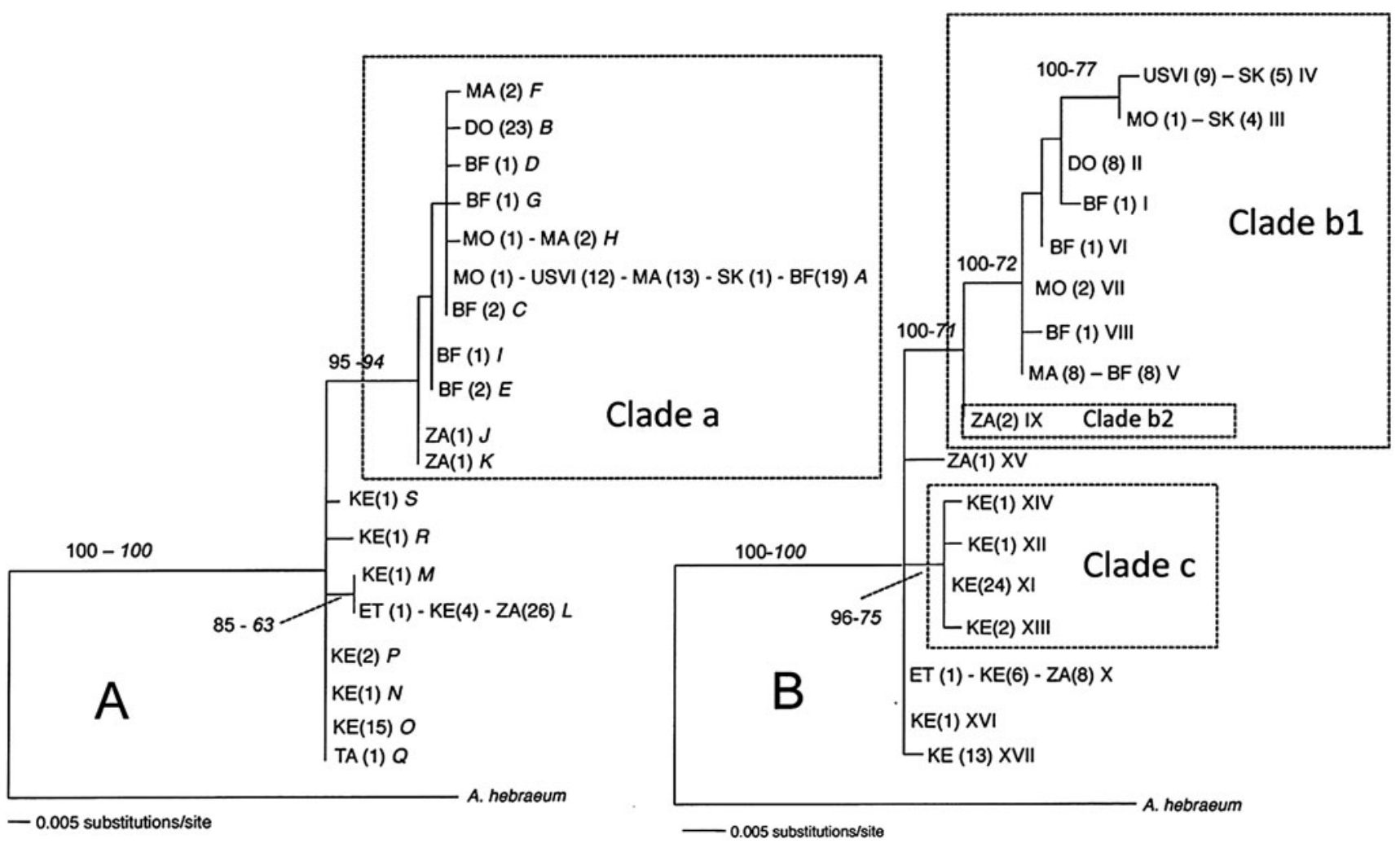

FIG. 3. Phylogenetic trees inferred by Bayesian analysis of the 12SrDNA (A), and the D-Loop (B) gene fragments in studied populations of Amblyomma variegatum. Numbers above the branches represent posterior probabilities and (in italics) bootstrap values obtained by maximum parsimony analysis. Origins of the haplotypes and their numbers (in parentheses) are designated as follows: MO, Montserrat; DO, Dominica; VI, U.S. Virgin Islands; MA, Mali; BF, Burkina Faso; SK, St. Kitts; KE, Kenya; ET, Ethiopia; ZA, Zambia. Letters in capital italics for 12 SrDNA and roman numerals for DL cross-reference the haplotypes as listed in Tables 2 and 3, respectively.

lineages. However, Caribbean haplotypes are found in the basal lineages of clade $d$, and West African haplotypes are found in the terminal clusters, indicating that most of these haplotypes have a very recent common origin.

\section{Haplotype statistical analyses}

The Caribbean samples were characterized by relatively high $12 \mathrm{~S}$ haplotype diversity $(\mathrm{Hd}=0.435)$, with very low $(\pi=0.0002)$ nucleotide diversity (Table 2$)$, which is indicative of recent population growth (Tajima 1989). Recent expansion would also be supported by Tajima's D significant negative values, not only for the Caribbean $(-1.473)$, but also for West Africa (-1.649) (Tajima 1989). Lack of significance $(-0.783$ for the Caribbean and -2.867 for West Africa/Caribbean) in the corresponding Fu's statistics would argue, however, for other possible mechanisms (e.g., selection) at play. The DL sequences are characterized by uniformly high haplotype diversity and low nucleotide diversity (Table 4). DL Fu's and Tajima's neutrality test results were all non-significant, indicating relative population stability for this marker. Strong differentiation between East and West African populations was supported by significant 12 SrDNA pairwise $\Phi_{\mathrm{ST}}$ values (Table 5). Among the Caribbean populations, only the Dominican population was distinct from western African populations, whereas $\Phi_{\mathrm{ST}}$ comparisons between all other
Caribbean and West African groups were not significant. The exact test of haplotype differentiation confirmed these findings (Table 5). Within the DL data matrix (Table 6), all populations were significantly distinct from each other, with the exception of the two West African samples. The 12S AMOVA (Table 7) showed that $61.8 \%$ of the variation in 12 SrDNA haplotype frequencies occurred among groups $(p=0.05), 13.9 \%$ among populations within groups ( $p \leq 0.001)$, and $24.3 \%$ within populations $(p \leq 0.001)$. In contrast, only $10.2 \%(p=0.09)$ of the DL variation in haplotype frequencies occurred among groups, $44.5 \%(p \leq 0.001)$ among populations within groups, and $44.2 \%$ $(p \leq 0.001)$ within populations (Table 7).

Mismatch distribution variations were calculated among haplotypes for the entire sample series, and for the West African, East African, and Caribbean samples separately. As neither Tajima's D nor Fu's Fs test detected population expansions in the DL data matrix, the mismatch distribution was estimated for only $12 \mathrm{SrDNA}$ sequences. The resulting graphs (Fig. 5) show that a pattern compatible with population expansion is evident in the Caribbean, and less markedly in the West African sample. The raggedness index test (Table 2) suggests that only the curves corresponding to all samples combined and to the East African sample differ significantly ( $p \leq 0.001$ and $p=0.02$, respectively) from their respective estimated curves, indicating that these populations are essentially stable. 


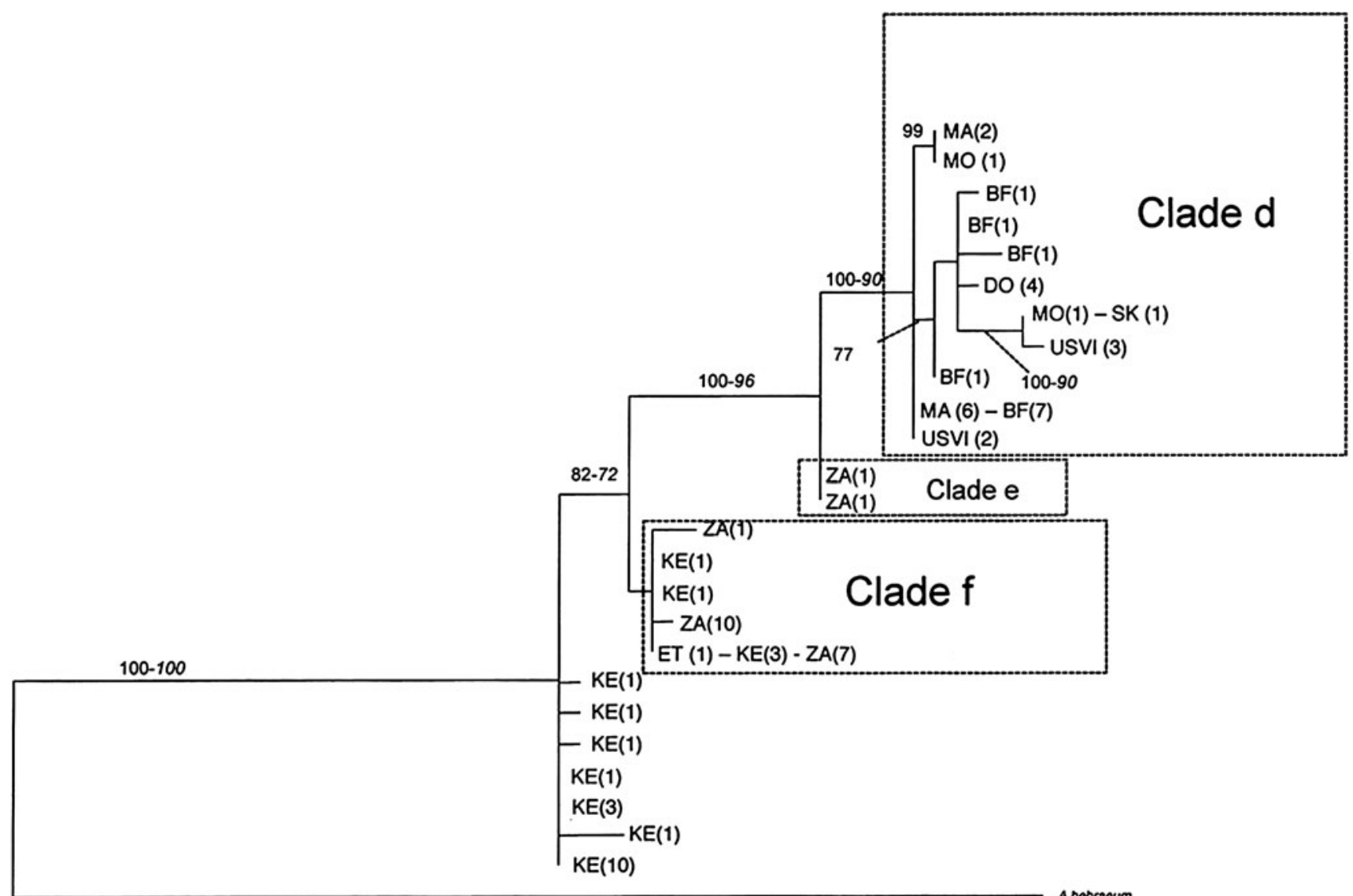

FIG. 4. Total evidence phylogenetic tree inferred by Bayesian analysis of the concatenated 12SrDNA and D-Loop sequences in studied populations of Amblyomma variegatum. Numbers above the branches represent posterior probabilities inferred by Bayesian analysis, and (in italics) bootstrap values obtained by maximum parsimony analysis. Origins of the haplotypes and their numbers (in parentheses) are designated as follows: MO, Montserrat; DO, Dominica; VI, U.S. Virgin Islands; MA, Mali; BF, Burkina Faso; SK, St. Kitts; KE, Kenya; ET, Ethiopia; ZA, Zambia.

\section{Discussion}

Data show that overall diversity in terms of studied polymorphic genetic sites within $A$. variegatum is low (5\% in both 12SrDNA and DL) when compared to genetic divergence within other Amblyomma taxa. Mixson and associates (2006) reported up to $7 \%$ polymorphic sites within Amblyomma americanum (Linnaeus) ticks collected in the state of Georgia (U.S.), and Trout and colleagues (2010) found 11\% polymorphic sites within A. americanum in Arkansas (U.S.). The observation that genetic diversity in each of two relatively local populations within $A$. americanum is higher than the diversity we found among widely distributed populations of A. variegatum is significant, especially because the former results were based on analysis of mitochondrial 16SrDNA gene sequences, which are usually less variable than the $12 \mathrm{SrDNA}$ sequences we studied (Norris et al. 1996). The low genetic diversity within a tick species, $A$. variegatum, with such an expansive geographic distribution is surprising, particularly when compared with another widely distributed congeneric

Table 4. Descriptive Statistics of Studied Amblyomma variegatum D-Loop Haplotypes

\begin{tabular}{lrrrccrrr}
\hline Region & & & & & & & \multicolumn{2}{c}{$\begin{array}{c}\text { Tajima's test } \\
D(\mathrm{p})\end{array}$} \\
\hline West Africa & $N s$ & $S$ & $k$ & $m p d \pm S D$ & $H d \pm S D$ & $\pi \pm S D$ & $\begin{array}{c}\text { Fu's Test } \\
F s(\mathrm{p})\end{array}$ \\
East Africa & 21 & 5 & 5 & $1.22 \pm 0.81$ & $0.414 \pm 0.124$ & $0.0028 \pm 0.0021$ & $-0.702(0.30)$ & $0.516(0.62)$ \\
Caribbean & 60 & 13 & 8 & $2.16 \pm 1.22$ & $0.731 \pm 0.032$ & $0.0050 \pm 0.0031$ & $-0.725(0.28)$ & $0.128(0.57)$ \\
West Africa + Caribbean & 29 & 6 & 4 & $2.13 \pm 1.22$ & $0.680 \pm 0.058$ & $0.0049 \pm 0.0031$ & $1.571(0.95)$ & $2.625(0.89)$ \\
Total & 50 & 8 & 7 & $2.77 \pm 1.49$ & $0.748 \pm 0.029$ & $0.0064 \pm 0.0038$ & $1,258(090)$ & $2.443(0.87)$ \\
& 110 & 19 & 17 & $5.12 \pm 2.50$ & $0.869 \pm 0.012$ & $0.0118 \pm 0.0064$ & $1.045(0.87)$ & $1.457(0.74)$ \\
\hline
\end{tabular}

Ns, number of sequences; $S$, segregating sites; $k$, number of observed haplotypes; mpd, mean number of pairwise differences \pm SD; Hd, haplotype or gene diversity $\pm \mathrm{SD} ; \pi$, nucleotide diversity/site $\pm S D ; p$ values in parentheses. Data obtained after removal of indels. 
Table 5. 12SrDNA Pairwise Comparison of Genetic Differentiation $\left(\Phi_{\mathrm{St}}\right)$ Among All Sampled Amblyomma variegatum populations Below the Diagonal

\begin{tabular}{|c|c|c|c|c|c|c|c|}
\hline Populations & 1 & 2 & 3 & 4 & 5 & 6 & 7 \\
\hline 1. Dominica & & ns & ns & ns & 0.02 & $<0.001$ & $<0.001$ \\
\hline 2. U.S. Virgin Island & 0.0000 & & ns & ns & ns & $<0.001$ & $<0.001$ \\
\hline 3. St. Kitts + Montserrat & 0.0730 & 0.008 & & ns & ns & $<0.001$ & $<0.001$ \\
\hline 4. Mali & 0.0620 & 0.021 & -0.024 & & ns & $<0.001$ & $<0.001$ \\
\hline 5. Burkina Faso & $0.158^{*}$ & 0.090 & -0.021 & 0.016 & & $<0.001$ & $<0.001$ \\
\hline 6. Kenya + Ethiopia & $0.743^{* * *}$ & $0.685^{* * *}$ & 0.853 & 0.794 & 0.757 & & $<0.001$ \\
\hline 7. Zambia & $0.925^{* * *}$ & $0.905^{* * *}$ & 0.635 & 0.624 & 0.555 & 0.639 & \\
\hline
\end{tabular}

${ }^{*} p \leq 0.05,{ }^{* * *} p \leq 0.001$ significantly above diagonal $p$ values for exact test of haplotype differentiation based on haplotype frequencies. ns, not significant.

cattle tick, Amblyomma cajennense (Fabricius), which is characterized by intra-specific $12 \mathrm{SrDNA}$ genetic variability of over $25 \%$ (Beati, unpublished data). Our data are comparable, however, to divergence values detected in the widespread tick Ixodes ricinus (Linnaeus) in Europe (Casati et al. 2008).

The lack of genetic diversity among all our samples indicates a relatively recent evolutionary common origin. Our generated phylogenies suggest that $A$. variegatum originated in East Africa and spread more recently to West Africa. The observation that ticks from both West Africa and the Caribbean still share a large number of haplotypes confirms historical evidence indicating that $A$. variegatum was exported from West Africa to the Caribbean in very recent times. It also means that the West African and Caribbean ticks still can be considered to belong genetically to a single population, although some DL haplotypes seem to have diversified in the Caribbean, with additional unique haplotypes further diverging from the predominant ones.

Low genetic diversity may be explained by the fact that all the ticks in our sample series were collected from cattle and not from wildlife. Host race formation is known in some tick species (McCoy et al. 2005; de Meeûs et al. 2010), and possibly a population of $A$. variegatum progressively became a specialist parasite of cattle, and it followed humans and cattle throughout the African continent in relatively recent times. This possibility is supported by evidence that establishment of pastoralism in Africa followed the same westward evolution (Hanotte et al. 2002). Another possible reason for the low genetic diversity in our $A$. variegatum samples is that ticks on African cattle have undergone a number of bottlenecks due to extensive applications of acaricides, resulting in the selection of a genetically homogeneous subset of ticks. By adding samples from wild animals, which were unfortunately not available, overall population patterns may have shown higher levels of diversity.

In terms of phylogeography, if we exclude the two Zambian intermediate haplotypes, the separation between West and East African A. variegatum samples is clear in the TCS minimum spanning networks (Figs. 1 and 2). The star-like topology of the more westerly 12SrDNA sequences suggests a rapid and recent population expansion for $A$. variegatum, with several haplotypes differing by a single base pair from the predominant haplotype, which has a large geographical distribution. In contrast, the East African samples are more diverse from each other and form a loop, which is more consistent with a fairly stable, homogeneous population. These findings and the high diversity in the Kenyan samples, which include the predominant haplotype $L$, support the notion of an origin of the species in that area, with a progressive population movement westward.

The split between East African and more westerly haplotypes, and the occurrence of an intermediary haplotype in Zambia, is common to both the 12 SrDNA and DL networks. However, in Figure 2, the DL West African/Caribbean sequences are organized in a loop with as much diversity between haplotypes as that observed in East Africa. The two studied genes represent, therefore, two slightly different aspects of the evolutionary histories within the two main A. variegatum population groups we recognize, probably due to differing mutation rates, but also reflected in a better

Table 6. D-Loop Pairwise Comparison of Genetic Differentiation $\left(\Phi_{\text {St }}\right)$ Among All Sampled Populations of Amblyomma VARIEgatum Below the Diagonal

\begin{tabular}{|c|c|c|c|c|c|c|c|}
\hline Populations & 1 & 2 & 3 & 4 & 5 & 6 & 7 \\
\hline 1. Dominica & & $<0.001$ & $<0.001$ & 0.002 & $<0.001$ & $<0.001$ & $<0.001$ \\
\hline 2. U.S. Virgin Island & $1.000^{* * *}$ & & 0.020 & $<0.001$ & $<0.001$ & $<0.001$ & $<0.001$ \\
\hline 3. St. Kitts + Montserrat & $0.607^{* *}$ & $0.371^{* * *}$ & & $<0.001$ & $<0.001$ & $<0.001$ & $<0.001$ \\
\hline 4. Mali & $1.000^{* * *}$ & $1.000^{* * *}$ & $0.534^{* * *}$ & & 0.29 & $<0.001$ & $<0.001$ \\
\hline 5. Burkina Faso & $0.543^{* * *}$ & $0.655^{* * *}$ & $0.285^{* * *}$ & 0.152 & ns & $<0.001$ & $<0.001$ \\
\hline 6. Kenya + Ethiopia & $0.625^{* * *}$ & $0.632^{* * *}$ & $0.422^{* * *}$ & $0.625^{* * *}$ & $0.452^{* * *}$ & & $<0.001$ \\
\hline 7. Zambia & $0.587^{* * *}$ & $0.597^{* * *}$ & $0.358^{* * *}$ & $0.587^{* * *}$ & $0.392^{* * *}$ & $0.395^{* * *}$ & \\
\hline
\end{tabular}

${ }^{* *} p \leq 0.01,{ }^{* * *} p \leq 0.001$ significantly above diagonal $p$ values for exact test of haplotype differentiation based on haplotype frequencies. ns, not significant. 
Table 7. Analysis of Molecular Variance (AMOVA) Calculated in ARLEQUiN for 12 SrDNA and D-Loop Genetic Sequences of Studied Amblyomma variegatum Groups and Populations

\begin{tabular}{|c|c|c|c|c|c|c|c|c|}
\hline AMOVA (1000 permutations) & $\begin{array}{c}12 S r D N A \\
\text { Variance }\end{array}$ & $\begin{array}{l}12 S r D N A \\
\% \text { Variation }\end{array}$ & $\begin{array}{c}12 S r D N A \\
\phi\end{array}$ & $\begin{array}{c}12 S r D N A \\
p\end{array}$ & $\begin{array}{c}D L \\
\text { Variance }\end{array}$ & $\begin{array}{c}D L \\
\% \text { Variation }\end{array}$ & $\begin{array}{c}D L \\
\phi\end{array}$ & $\begin{array}{c}D L \\
p\end{array}$ \\
\hline Among all groups & 0.29 & 61.84 & 0.618 & 0.05 & 0.05 & 10.20 & 0.102 & 0.09 \\
\hline Among populations within groups & 0.07 & 13.88 & 0.364 & $<0.001$ & 0.22 & 44.55 & 0.496 & $<0.001$ \\
\hline Within populations & 0.11 & 24.27 & 0.757 & $<0.001$ & 0.23 & 44.25 & 0.547 & $<0.001$ \\
\hline
\end{tabular}

Significant values in bold. Groups defined as East (2 populations: Kenya + Ethiopia and Zambia) and West (3 populations: Mali, Burkina Faso, and all Caribbean samples). $\phi$, pairwise genetic distances; $p$, significance value.

resolution in the most recent divergence events in the DL phylogenetic tree. Our TCS and phylogenetic analyses suggest that $A$. variegatum reached West Africa through Zambia. We would note, however, that we did not analyze specimens from Central African countries, and so we cannot exclude the possibility that the genetically different populations from this area were the source of the migration to West Africa. Our findings generally support the phylogenetic relationships reported between E. ruminantium isolates from Africa and the Caribbean (Alsopp et al. 2003). In the case of E. ruminantium, however, there was also a relationship between Caribbean and South African strains, and it was noted that animals may have been transferred from South Africa to the Caribbean in the 17th-18th centuries (Allsopp et al. 2003). As the vector of E. ruminantium is A. hebraeum in South Africa, and A. variegatum does not occur in the country (Walker and Olwage 1987), we could not use our data to further evaluate the possible transfer of animals from South Africa to the Caribbean.

Our AMOVA analysis indicates that there is significant differentiation at all levels within 12SrDNA sequences, while within DL sequences, the contrasting lack of structure between the two main geographical groups is surprising, given
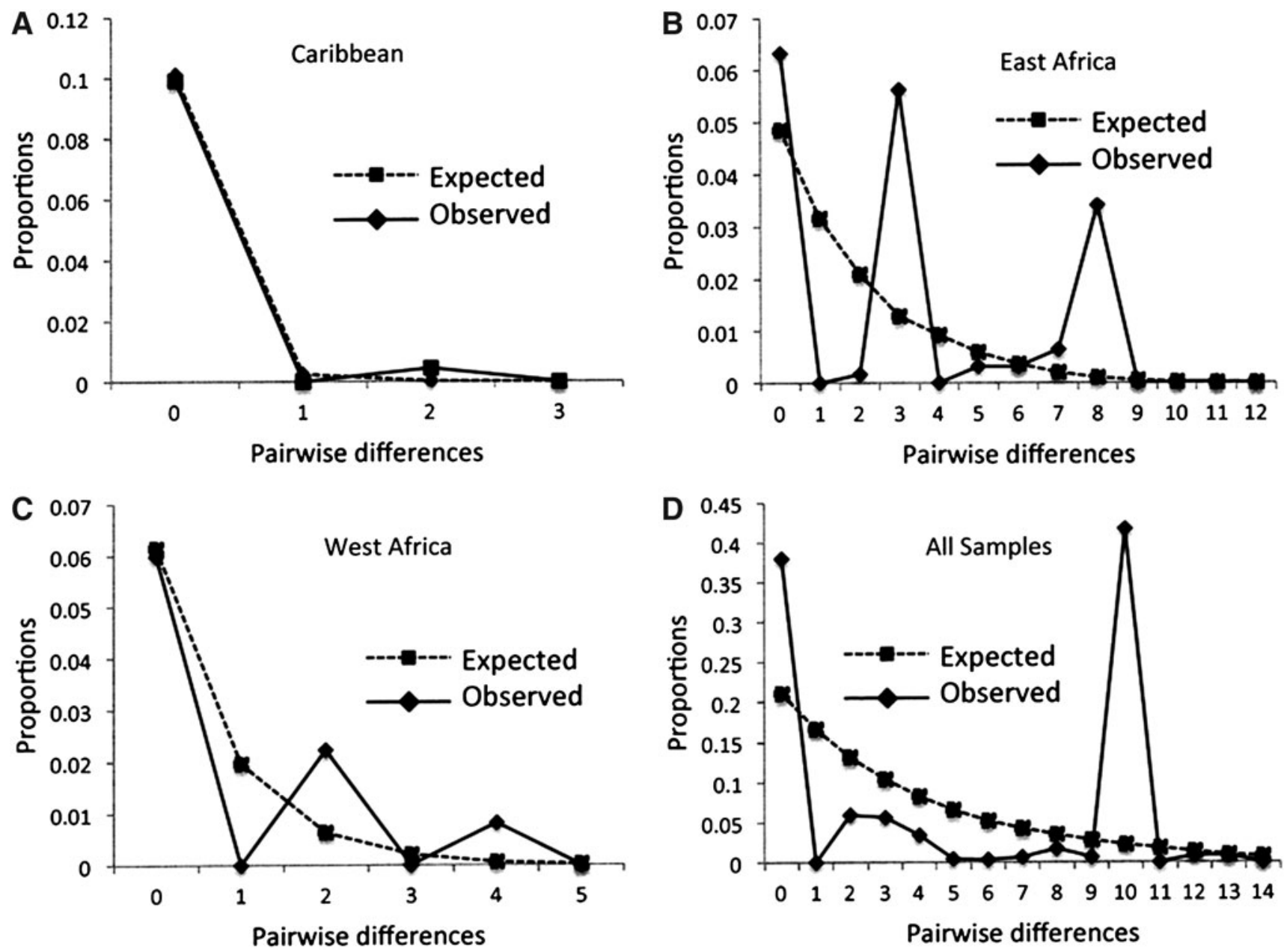

FIG. 5. Mismatch distributions of the observed variation in 12SrDNA haplotypes of studied Amblyomma variegatum populations compared to the theoretical distributions expected for population expansion in (A) the Caribbean, (B) East Africa, (C) West Africa, and (D) all samples combined. 
the fact that there are a large number of haplotypes confined to each geographical area. The overpowering level of DL variation detected between and within studied A. variegatum populations seems to have obfuscated the real geographical gap between the two groups. The signals of demographic expansion in $12 S$ sequences detected by Tajima's D for the Caribbean and the combined West African/Caribbean populations are not confirmed by Fu's statistics, indicating that other mechanisms, such as selection, may have affected haplotype distributions. Nevertheless, 12SrDNA mismatch distributions in the Caribbean and West Africa show that the observed curves (Fig. 5A and C) do not differ significantly from the expected ones, an indication of population expansion.

Our studies show that genetic diversity within observed A. variegatum populations is low, which provides useful clues to their recent evolutionary history. Our data suggest a progressive westward expansion of this tick species. The phylogenies are shallow, particularly in the westerly lineages. Analyses of two studied genes support an east-west genetic separation, with Caribbean genetic sequences being associated with and often identical to West African haplotypes, and East African sequences standing apart. Thus our data confirm the reputed West African origin of Caribbean A. variegatum populations. The fact that ticks in West Africa and the Caribbean still share so many haplotypes, and perhaps our incomplete sampling in the islands and from wild hosts, prevented us from finding a clear migratory pattern within the Caribbean Basin.

\section{Acknowledgments}

This study was supported through a Ross University School of Veterinary Medicine Intramural Research Grant, and in part by NSF grant \#1026146 to L. Beati.

\section{Author Disclosure Statement}

No competing financial interests exist.

\section{References}

Adakal H, Meyer DF, Carasco-Lacombe C, et al. MLST scheme of Ehrlichia ruminantium: Genomic stasis and recombination in strains from Burkina-Faso. Infect Genet Evol 2009; 9:13201328.

Allsopp MTEP, Van Heerden H, Steyn HC, et al. Phylogenetic relationships among Ehrlichia ruminantium isolates. Ann NY Acad Sci 2003; 990:685-691.

Allsopp MT, Van Strijp MF, Faber E, et al. Ehrlichia ruminantium variants which do not cause heartwater found in South Africa. Vet Microbiol 2007; 120:158-166.

Andrew HR, Norval RAI. The carrier status of sheep, cattle and African buffalo recovered from heartwater. Vet Parasitol 1989; 34:261-266.

Barré N, Camus E, Fifi J, et al. Tropical bont tick eradication campaign in the French Antilles. Current status. Ann NY Acad Sci 1996; 791:64-76.

Barré N, Garris G, Camus E. Propagation of the tick Amblyomma variegatum in the Caribbean. Rev Sci Tech Off Int Epiz 1995; 14:841-855.

Beati L, Cáceres AG, Lee JA, et al. Systematic relationships among Lutzomyia sand flies (Diptera: Psychodidae) of Peru and Colombia based on the analysis of $12 \mathrm{~S}$ and $28 \mathrm{~S}$ ribosomal DNA sequences. Int J Parasitol 2004; 34:225-234.
Beati L, Keirans JE. Analysis of the systematic relationships among ticks of the genera Rhipicephalus and Boophilus (Acari: Ixodidae) based on mitochondrial $12 S$ ribosomal DNA gene sequences and morphological characters. J Parasitol 2001; 87:32-48.

Beati L, Kelly PJ, Matthewman LA, et al. Prevalence of rickettsialike organisms and spotted fever group rickettsiae in ticks (Acari: Ixodidae) from Zimbabwe. J Med Entomol 1995; 32: 787-792.

Black WC, Roehrdanz RL. Mitochondrial gene order is not conserved in arthropods: prostriate and metastriate tick mitochondrial genomes. Mol Biol Evol 1998; 15:1772-1785.

Camus E, Barré N. Vector situation of tick-borne diseases in the Caribbean islands. Vet Parasitol 1995; 57:167-176.

Casati S, Bernasconi MV, Gern L, et al. Assessment of intraspecific mtDNA variability of European Ixodes ricinus sensu stricto (Acari: Ixodidae). Infect Genet Evol 2008; 8:152-158.

Clement M, Posada D, Crandall K. TCS: A computer program to estimate gene genealogies. Mol Ecol 2000; 9:1657-1660.

Corn JL, Barré N, Thiebot B, et al. Potential role of cattle egrets, Bulbucus ibis (Ciconiformes: Ardeidae), in the dissemination of Amblyomma variegatum (Acari: Ixodidae) in the eastern Caribbean. J Med Entomol 1993; 30:1029-1037.

Deem SL. A review of heartwater and the threat of introduction of Cowdria ruminantium and Amblyomma spp. ticks to the American mainland. J Zoo Wildlife Med 1998; 29:109-113.

de Meeûs T, Koffi BB, Barré N, et al. Swift sympatric adaptation of a species of cattle tick to a new deer host in New Caledonia. Infect Gen Evol 2010; 10:976-983.

Estrada-Peña A, Pegram RG, Barré N, et al. Using invaded range data to model the climate suitability for Amblyomma variegatum (Acari: Ixodidae) in the New World. Exp Appl Acarol 2007; 41:203-214.

Excoffier L, Laval G, Schneider S. Arlequin ver. 3.0: An integrated software package for population genetics data analysis. Evol Bioinformatics Online 2005; 1:47-50.

Excoffier L, Smouse PE, Quattro JM. Analysis of molecular variance inferred from metric distances among DNA haplotypes: Application to human mitochondrial DNA restriction data. Genetics 1992; 131:479-491.

$\mathrm{Fu}$ YX. Statistical tests of neutrality of mutations against population growth, hitchhiking and background selection. Genetics 1997; 147:915-925.

Hanotte O, Bradley DG, Ochieng JW, et al. African pastoralism: genetic imprints of origins and migrations. Science 2002; 296:336-339.

Hickson RE, Simon C, Cooper A, et al. Conserved sequence motifs, alignment, and secondary structure for the third domain of the animal 12SrRNA. Mol Biol Evol 1996; 13:150-169.

Huelsenbeck JP, Ronquist F, Nielsen R, et al. Bayesian inference of phylogeny and its impact on evolutionary biology. Science 2001; 294:2310-2314.

Kelly PJ, Beati L, Mason PR, et al. Rickettsia africae sp. nov., the etiological agent of African tick bite fever. Int J Syst Bacteriol 1996; 46:611-614.

Kelly PJ, Lucas H, Beati L, et al. Survey for Rickettsia africae in Amblyomma variegatum and domestic ruminants on eight Caribbean islands. J Parasitol 2010; 96:1086-1088.

Maddison DR, Maddison WP. McClade 4: Analysis of phylogeny and character evolution. Sinauer Associates, Sunderland, MA (CD-ROM), 2000.

Maillard JC, Maillard N. Historique du peuplement bovin et de l'introduction de la tique Amblyomma variegatum dans les îles françaises des Antilles: synthèse bibliographique. Ethnozootechnie 1998; 61:19-35. 
McCoy KD, Chapuis E, Tirard C, et al. Recurrent evolution of host-specialized races in a globally distributed parasite. Proc R Soc B 2005; 272:2389-2395.

McCoy KD. The population genetic structure of vectors and our understanding of disease epidemiology. Parasite 2008; 15: 444-448.

McLain DK, Wesson DM, Collins FH, et al. Evolution of the rDNA spacer, ITS 2, in the ticks Ixodes scapularis and I. pacificus (Acari: Ixodidae). Heredity 1995; 75:303-319.

Mixson TR, Lydy SL, Dasch GA, et al. Inferring the population structure and demographic history of the tick, Amblyomma americanum Linnaeus. J Vector Ecol 2006; 31:181-192.

Molia S, Frebling M, Vachiéry N, et al. Amblyomma variegatum in cattle in Marie Galante, French Antilles: Prevalence, control, measures, and infection by Ehrlichia ruminantium. Vet Parasitol 2008; 153:338-346.

Norris DE, Klompen JSH, Keirans JE, et al. Population genetics of Ixodes scapularis (Acari: Ixodidae) based on mitochondrial $16 \mathrm{~S}$ and $12 \mathrm{~S}$ genes. J Med Entomol 1996; 33:78-89.

Parola P, Vestris G, Martinez D, et al. Tick-borne rickettiosis in Guadeloupe, the French West Indies: isolation of Rickettsia africae from Amblyomma variegatum ticks and serosurvey in humans, cattle, and goats. Am J Trop Med Hyg 1999; 60:888-893.

Pegram R, de Castro JJ, Wilson DD. The CARICOM/FAO/IICA Caribbean Amblyomma Program. Ann NY Acad Sci 1998; 849:343-348.

Pegram R, Indar L, Eddi C, et al. The Caribbean Amblyomma Program: Some ecological factors affecting its success. Ann NY Acad Sci 2004; 1026:302-311.

Posada D, Crandall KA. MODELTEST: Testing the model of DNA substitution. Bioinformatics 1998; 14:817-818.

Qiu W-G, Dykhuizen DE, Acosta MS, et al. Geographic uniformity of the Lyme disease spirochete (Borrelia burgdorferi) and its shared history with tick vector (Ixodes scapularis) in the northeastern United States. Genetics 2002; 160:833-849.

Raymond M, Rousset F. An exact test for population differentiation. Evolution 1995; 49:1280-1283.
Rogers A. Population forecasting: Do simple models outperform complex models? Math Pop Studies 1995; 5:187-202.

Schneider S, Roessli D, Excoffier L. Arlequin version 2.000: A software for population genetic data analysis. Geneva, Switzerland, Genetics and Biometry Laboratory, University of Geneva; 2000.

Swofford DL. PAUP* Phylogenetic analysis using parsimony (*and other methods). Version 4.0. Sunderland, Massachusetts, Sinauer Associates; 2000.

Tajima F. Statistical method for testing the neutral mutation hypothesis by DNA polymorphism. Genetics 1989; 123: 585-595.

Trout RT, Steelman CD, Szalanski AL. Population genetics of Amblyomma americanum (Acari: Ixodidae) collected from Arkansas. J Med Entomol 2010; 47:152-161.

Uilenberg G, Barré N, Camus E, et al. Heartwater in the Caribbean. Prev Vet Med 1984; 2:255-267.

Vachiéry N, Jeffery H, Pegram R, et al. Amblyomma variegatum ticks and heartwater on three Caribbean Islands. Ann NY Acad Sci 2008; 1149:191-195.

Walker JB, Olwage A. The tick vectors of Cowdria ruminantium (Ixodoidea, Ixodidae, genus Amblyomma) and their distribution. Onderstepoort J Vet Res 1987; 54:353-379.

Zhang D-X, Hewitt GM. Insect mitochondrial control region: a review of its structure, evolution, and usefulness in evolutionary studies. Biochem Syst Ecol 1997; 25:99-120.

Address correspondence to: Lorenza Beati Institute of Arthropodology and Parasitology Georgia Southern University 75 Georgia Avenue Building 204

P.O. Box 8056

Statesboro, GA 3046

E-mail: lorenzabeati@georgiasouthern.edu 